\title{
Kiai Haji Ahmad Shah: Peranannya dalam Memantapkan Perkembangan Islam di Johor
}

\author{
Siti Maimon Md Sirat ${ }^{a}{ }^{*}$, Farahwahida Mohd Yusof ${ }^{b}, K^{2}$ assim Thukimanc, Saleha Sacckania \\ ${ }^{a}$ Fakulti Tamadun Islam, Universiti Teknologi Malaysia, 81310 UTM Johor Bahru,Johor, Malaysia \\ ${ }^{b}$ Pusat Penyelidikan Figh Sains dan Teknologi (CFIRST), Universiti Teknologi Malaysia, 81310 UTM Johor Bahru,Johor, Malaysia \\ 'Fakulti Pengurusan, Universiti Teknologi Malaysia, 81310 UTM Johor Bahru,Johor, Malaysia
}

*Corresponding author: smaimon3@live.utm.my

\begin{abstract}
In the development of a society and a nation-state, the aspect of leadership plays a key role. Moreover, the leadership comes from the figures who are called ulama' or Muslim scholars. Kiai Haji Ahmad Shah is a renowned scholar in Johor. He served as Cadi or an Islamic Judge in several districts in Johor before being appointed Chief Islamic Judge of Johor. He was born in 1901 in Kampung Rimba Terjun, Pontian, Johor. His excellence in mastering various fields of knowledge and the talent of leadership began since childhood. His personal excellence attracted the public to explore the teachings of Islam, and he became a role model to amny leaders as well as murabbi or educators of today. The persistence of Kiai Haji Ahmad Shah in facing the challenge of developing and strengthening the faith of Muslims in the era before independence were the main focus of this study. This also shows the Islamic leadership in Kiai Haji Ahmad Shah; a leader who really believes in the "Leadership by Example"
\end{abstract}

Keywords: Leadership, Muslim scholars, Kiai Haji Ahmad Shah, cadi

\begin{abstract}
Abstrak
Dalam pembinaan sebuah masyarakat dan negara-bangsa, aspek kepimpinan memainkan peranan utama. Lebih-lebih lagi kepimpinan itu datang dari tokoh yang bergelar ulama. Kiai Haji Ahmad Shah merupakan tokoh ulama terkenal di Johor. Beliau pernah menjawat jawatan sebagai kadi di beberapa daerah di negeri Johor sebelum dilantik menjadi Kadi Besar Johor. Dilahirkan pada tahun 1901 di Kampung Rimba Terjun, Pontian, Johor. Kecemerlangannya menguasai ilmu dalam pelbagai bidang dan bakat kepimpinannya mula terserlah seawal zaman kanak-kanak lagi. Keunggulan peribadinya berjaya menarik minat masyarakat untuk mendalami ajaran Islam, bahkan beliau menjadi contoh ikutan kepada pemimpin dan para murabbi dewasa ini. Kegigihan Kiai Haji Ahmad Shah berhadapan dengan cabaran dalam membangunkan dan mengukuhkan akidah masyarakat Islam pada era sebelum merdeka diberi tumpuan utama dalam kajian ini. Hal ini sekaligus memperlihatkan ketokohan kepimpinan ulama yang ada pada diri Kiai Haji Ahmad Shah; seorang pemimpin yang benar-benar berpegang kepada prinsip 'Kepimpinan Melalui Teladan.'
\end{abstract}

Kata kunci: Kepimpinan, ulama, Kiai Haji Ahmad Shah, kadi

(C) 2018 Penerbit UTM Press. All rights reserved

\subsection{PENGENALAN}

Islam diturunkan sebagai rahmat bagi seluruh alam khususnya untuk manusia. Oleh itu persoalan pemimpin dan kepimpinan merupakan persoalan pokok dalm ajarannya. Sejarah telah membuktikan agama Islam berkembang sejak dari zaman Rasulullah SAW melalui dakwah para daei bagi memastikan kelestarian dan kesinambungannya hingga ke akhir zaman. Manakala ulama adalah penyampai ajaran Allah SWT dan rasulNya sebagai pemelihara kesucian Islam. Sudah menjadi tradisi Islam, institusi ulama memiliki kedudukan yang tersendiri untuk diikuti dan dicontohi. Selaras dengan keutuhan kedudukan itu, Kiai Haji Ahmad Shah merupakan seorang tokoh ulama serba boleh yang wajar dikenali ciri-ciri dan latar belakangnya.

Ahmad Shah bin Abdul Jabar dilahirkan di Kampung Rimba Terjun, Pontian pada tahun 1901. Beliau merupakan anak sulung daripada empat orang adik beradik. Ayahnya Abdul Jabar adalah ahli sufi yang datang ke Tanah Melayu dari Demak di Indonesia. Beliau datang bersama bapanya Omar bin Othman serta ibunya Marwiyah binti Abdul Ghafur. Mereka berhijrah ke Tanah Melayu sebagai menyambut usaha dan dasar memajukan Johor di zaman Temenggung Abu Bakar yang membawa masuk pekerja luar terutamanya daripada Indonesia untuk bekerja dan membuka kebun. Ketika itu jutawan Arab bernama Al-Sagoff, pemilik Syarikat Constantinople, juga sahabat baik kepada Temenggung Abu Bakar mendapat konsesi membuka ladang yang luas di daerah Pontian. Orang-orang Jawa dibawa masuk melalui 'Sistem Sheikh'. Menerusi sistem tersebut, kemudahan menunaikan fardu haji diberikan kepada pekerja Jawa dari Indonesia melalui tabungan upah bekerja di ladang kelapanya di Pontian. 


\subsection{OBJEKTIF}

Kajian ini bertujuan:

2.1 Mengenengahkan biodata tokoh, latar belakang pendidikan, watak dan keperibadiannya.

2.2 Mengenalpasti nilai-nilai kepimpinan dan sumbangannya yang boleh dicontohi.

2.3 Menjadikan bahan rujukan sejarah sebagai tokoh agama di negeri Johor.

\subsection{METODOLOGI}

Kajian dijalankan menggunakan metode kualitatif dengan pendekatan sejarah. Ini bertujuan meneroka tingkah laku, perspektif, perasaan dan pengalaman hidup tokoh yang dikaji. Metode temu bual pula dilaksanakan terhadap anak-anak, adik, sanak saudara, anak murid, orang yang mengenali tokoh ini dan metode dokumentasi pula diperolehi di arkib, perpustakaan dan orang perseorangan. Reka bentuk yang paling sesuai ialah biografi kerana kajian ini berkaitan dengan kehidupan seseorang individu. Kajian ini berperingkat dari tokoh yang dikaji itu lahir, pendidikan asas yang diperolehi, pendidikan di peringkat remaja, tindakan yang diambil setelah menjadi kadi di beberapa daerah di Johor, kehidupan berkeluarga sehinggalah beliau meninggal dunia yang bertujuan mencungkil dan memahami serta mendeskripsikan tentang keunikan kehidupan tokoh agama ini sebagai sosok peribadi yang perlu dicontohi dalam konteks perkembangan Islam di negeri Johor. Di samping dapat meningkatkan apresiasi terhadap kontribusi tokoh ini dalam bidang yang ditekuninya iaitu memperkenalkan Tareqat Qadiriyah Naqsyabandiah dan meneladani pengembangan ketrampilan pemikirannya yang kreatif dan kritis bagi memastikan syiar Islam tersebar dan diamalkan mengikut al-Quran dan al-sunnah. Apabila reka bentuk kajian telah dikenalpasti, barulah metode pengumpulan data dilaksanakan. Data yang dikumpulkan diklasifikasikan kepada metode dokumentasi dan metode temubual. Temu bual direkod dengan cara mencatat nota dan merakam seberapa banyak maklumat semasa temu bual. Setelah itu nota deskriptif dihasilkan tentang tindak balas lisan dan bukan lisan, serta pandangan tentang temu bual tersebut. Pengurusan data dilaksanakan bagi membersihkan data, memahami data dengan bantuan perisian computer NVivo versi 7. Penganalisisan data kualitatif melibatkan dua teknik iaitu analisis kandungan dan analisis berasaskan perkataan bagi mendapatkan kesimpulan. Bagi mendapatkan keesahan dan kebolehpercayaan kajian triangulasi data dilaksanakan serta mendapatkan pengesahan responden terhadap temubual. Akhir sekali barulah dicatatkan laporan.

\subsection{PENDIDIKAN}

Ahmad Shah mendapat pendidikan asas agama iaitu al-Quran dan ilmu Tasawuf dari bapanya sendiri yang dikenali sebagai Pak Imam Jabar. Beliau memulakan pendidikan asasnya di Sekolah Melayu Rimba Terjun pada tahun 1909 ketika berumur lapan tahun. Dari kecil bakat beliau telah terserlah walaupun agak nakal. Beliau sering mengungguli kelas mengatasi rakan-rakannya yang lain, sekalipun sering diarah menjadi tukang masak oleh gurunya dan menyediakan makanan bagi pelajar-pelajar lain.

Menyedari hakikat kepentingan ilmu dalam membentuk keperibadian dan masa depan seseorang, Pak Imam Jabar telah menghantar anaknya Ahmad Shah ke Sumatera dalam usaha melengkapkan diri anaknya dengan ilmu pengetahuan dan pengalaman. Melalui guru pertama yang ditemuinya, Ahmad Shah lebih banyak memberi tumpuan kepada ilmu keduniaan. Di sini Ahmad Shah diajar seni mempertahankan diri dalam bentuk ilmu persilatan yang disebut Silat Cimande.

Ahmad Shah kemudiannya meneruskan pengajian agama di Medan dan Deli, Sumatera. Beliau juga pernah berguru dengan Syeikh Zarkasi Barjan, Puwarejo, Jawa Tengah dan Syeikh Hasan Ma'ruf Kebumen, Jawa Tengah di sekitar tahun 1927 hingga 1930. Pengetahuannya dirasakan tidak mencukupi, lantas beliau pergi ke Damsyik untuk mendalami Ilmu Fiqh dan Tasawuf. Di Mekah beliau berguru dengan Syaikh Ahmad Khatib al-Sambasi, iaitu pengarang kitab 'Fathul 'Arifin'. Setelah merasakan ilmu yang dituntut mantap, Ahmad Shah kembali ke kampungnya untuk menyebarkan ilmu yang diperolehinya.

Daripada pernyataan di atas, ternyata Kiai Ahmad Shah memperolehi pendidikan secara formal dan tidak formal seawal usia muda lagi. Selain itu, pengalaman beliau sebagai anak Pak Imam Jabar dan juru nikah yang banyak menyelesaikan masalah sosial merupakan pendidikan yang amat tekal sebagai pembentuk keperibadiannya yang luhur.

\subsection{KEHIDUPAN BERKELUARGA}

Sikap dan tingkah laku Ahmad Shah telah memikat hati bekas gurunya Syeikh Abdul Karim Tamin. Beliau dijodohkan dengan anak angkatnya bernama Aishah dan dikurniakan lapan orang anak, iaitu lima orang lelaki dan tiga orang perempuan. Ahmad Shah mengamalkan poligami dalam kehidupan berkeluarga. Sepanjang kehidupannya beliau telah bernikah dengan lima orang isteri. Tetapi dalam sesuatu masa perkahwinan, isteri beliau tidak melebihi tiga orang sahaja. Setelah bernikah dengan Aishah, Ahmad Shah kembali ke kampung halamannya dan menikahi seorang wanita bernama Khadijah. Bersama Khadijah, beliau memperolehi lima orang anak, iaitu tiga orang perempuan dan dua orang lelaki.

Semasa menjadi Kadi di Pontian, beliau bernikah dengan seorang perempuan yang bekerja sebagai pelakon dan penari wayang bangsawan bernama Sairah. Tujuan perkahwinannya adalah untuk menyelamatkan kehidupan perempuan ini dan membawanya kembali kepada kehidupan cara Islam. Mereka dikurniakan seorang anak perempuan dan akhirnya mereka berpisah. Anak tersebut dipelihara oleh Ahmad Shah.

Begitu juga semasa beliau menjadi Kadi Batu Pahat, Ahmad Shah mengahwini seorang lagi bernama Aishah, perempuan berketurunan Arab. Setelah mendapat seorang cahaya mata perempuan mereka berpisah dan anak tersebut dipelihara oleh Ahmad Shah. Apabila menjadi Kadi Muar, beliau berkahwin seorang gadis bernama Kartini dan memperolehi tiga orang anak. Sehingga akhir hayatnya, Ahmad Shah hanya mempunyai lima orang isteri iaitu Aishah, Khadijah, Sairah, Aishah dan Kartini. Sebilangan besar anak-anak beliau berjaya dalam pendidikan dan memegang jawatan tinggi dalam sektor kerajaan dan swasta. 


\subsection{KEPERIBADIAN HAJI AHMAD SHAH}

Meneliti keperibadiannya, Ahmad Shah seorang yang peramah dan penyayang. Tetapi aura yang dimilikinya membuatkan orang yang baru mendekatinya akan berasa gerun. Setelah biasa bergaul, barulah terasa keprihatinan dan kasih sayangnya.

Beliau merupakan ulama yang dikenali oleh murid-muridnya sebagai seorang yang baik hati, pemurah, tidak memilih kesenangan hidup di dunia dan sentiasa beramal dengan ilmunya. Setelah bersara dari jawatan Kadi Besar Johor, beliau menjadi petani dan telah mendermakan hasil sawah padi di belakang rumahnya sebanyak 3,000 gantang padi kepada masjid dan surau di daerah Pontian.

Apabila bercakap atau memberi penerangan, beliau banyak menggunakan bahasa yang lembut dan perumpamaan atau kiasan. Setiap kata-katanya memaksa orang lain berfikir maksud di sebaliknya. Ini bersesuaian dengan karektor seorang syeikh dalam tareqat sebagaimana pendekatan sufisme yang dibawanya. Ini ditambah pula dengan rupa parasnya yang mirip kearaban. Daripada segi fizikal, sosok tubuhnya tinggi lampai, berkumis, janggut dan jambang suku inci berwarna kelabu yang tebal memenuhi pipi dan dagunya, bermata kelabu dan bercakap dalam dialek Jawa yang pekat.

Selain daripada memiliki daya ingatan yang kuat, Ahmad Shah amat mengasihi dan menghormati orang-orang tua serta memuliakan ulama dan guru-gurunya. Beliau juga tidak suka mencela orang tetapi banyak menumpukan kepada beribadat. Dalam hal pengamalan beribadat, Kiai Haji Ahmad Shah begitu tekun, setia dan istiqamah. Beliau beribadah sepanjang malam seperti mendirikan solat sunat dan berzikir sehingga waktu subuh. Beliau tidak banyak tidur. Tidurnya sekadar beberapa minit dalam keadaan duduk. Selain itu, beliau juga tahan berpuasa selama setahun, kecuali hari-hari yang dilarang berpuasa mengikut syariat Islam.

Sekalipun bersifat penyayang, Ahmad Shah seorang yang tegas mempertahankan prinsip-prinsip ilmu dan akidah Islam yang dipelajarinya. Hal ini digambarkan tentang sikap dan pemikirannya terhadap kehidupan masyarakat Melayu yang tidak serasi dengan ajaran Islam. Di samping itu, beliau menunjukkan sifat keprihatinan yang tinggi terhadap masalah masyarakat ketika itu. Ini menunjukkan beliau adalah pemimpin yang tegas mempertahankan kebenaran dan menentang kebatilan.

\subsection{KEPIMPINANNYA}

Kiai Haji Ahmad Shah telah membina satu nama yang besar kepada masyarakat di negeri Johor. Beliau telah menzahirkan contoh kepimpinan seorang ulama yang berpegang teguh dengan ajaran agama Islam. Beliau sentiasa mengajak masyarakat agar mempunyai kebersihan hati nurani menerusi amalan hidup sufi agar dapat mengetahui hakikat Allah SWT dan rahsia alam semesta yang amat bermakna sekali.

Kepimpinan beliau yang paling signifikan ialah dalam bidang pendidikan asas keluarga. Hal ini diberi penekanan olehnya sepanjang siri ceramah dan pengajaran dalam kuliahnya. Beliau memegang prinsip yang kukuh menekankan pendidikan yang dimainkan oleh keluarga dalam pembentukan sahsiah seseorang. Dalam erti kata lain, pendidikan awal kanak-kanak yang bermula dari rumah merupakan asas kepada pembentukan sahsiah yang kukuh bagi seseorang individu. Untuk itu ibu bapa perlu celik al-Quran dan hadis serta mengamalkan juga membacanya walau satu ayat sehari seperti yang dilaluinya dan dipelajari dari kedua ibu bapanya. Kiai Haji Ahmad Shah telah mengadakan banyak kelas agama dan pengajian al-Quran di beberapa buah surau dan masjid di daerah Pontian. Ia diadakan sebanyak dua kali seminggu setelah kembali dari Mekah pada tahun 1930-an.

Kiai Haji Ahmad Shah seorang yang berani mempertahankan perkara yang benar semasa memegang jawatan kadi dengan mengkritik pelaksanaan dasar pentadbiran Agama Islam Johor yang tidak menepati kehendak syariat Islam. Tindakan beliau telah memberi semangat kesedaran dalam kalangan masyarakat Islam agar bersatu-padu menentang penjajahan Jepun yang zalim dan tidak berperikemanusiaan. Keadaan ini berlaku pada tahun 1940, Haji Ahmad Shah telah bertukar menjadi Kadi di Mersing. Ketika berlakunya pendudukan Jepun di Tanah Melayu, kedudukannya sebagai Kadi telah tergugat dan tercabar. Beliau dipaksa mematuhi arahan pemerintah Jepun. Beliau sedar banyak arahan tentera Jepun yang bertentangan dengan akidah dan ajaran Islam. Majoriti rakyat hidup menderita disebabkan kekurangan makanan di bawah penjajahan Jepun. Orang Islam yang kematian ahli keluarganya pula diarahkan oleh pentadbiran Jepun membayar seratus ringgit bagi mengisi tabung perbendaharaan. Sebagai Kadi yang bertanggungjawab mempertahankan hak Agama Islam dan penganutnya, beliau telah membantah arahan tersebut. Ini disebabkan orang-orang Islam telah menderita akibat Perang Dunia Kedua dan mereka tidak patut dibebani dengan bayaran tersebut. Ahmad Shah telah menandatangani surat perletakan jawatan sebagai Kadi, bagi menyahut cabaran Haji Mohd Amin Karea (Gabenor Jepun di Johor) pada waktu itu jika tidak bersetuju dengan arahan yang diberi.

Keberaniannya ini menyebabkan masyarakat Islam di Johor mengakui bahawa Ahmad Shah mempunyai pegangan hidup Islam yang kukuh dan mempunyai jati diri yang tinggi dalam mempertahankan perkara yang benar dan menolak yang batil (salah).

Penguasaan ilmu pengetahuan yang mantap dalam ilmu tasawuf yang dipraktikkan beliau sebagai pemimpin atau guru mampu menghasilkan anak-anak didik yang berwibawa. Kepimpinan Ahmad Shah juga amat terserlah dalam bidang sosial. Beliau menggunakan kebijaksanaan yang dimilikinya untuk menarik minat orang ramai kembali kepada ajaran Islam yang syumul. Semasa menjadi Kadi Besar Johor, Ahmad Shah sentiasa berfikir untuk menarik kakitangan kerajaan yang leka dengan keduniaan kembali kepada kehidupan yang dikehendaki Islam. Sebelum negara mencapai kemerdekaan, kebanyakan ketua-ketua jabatan menjadikan arak sebagai minuman yang menjadi kebanggaan. Beliau sentiasa berfikir bagaimana hendak mengembalikan cahaya Islam dalam kehidupan mereka yang tidak menunaikan solat lima waktu dan solat Jumaat.

Ketika itu negara sedang menuju ke arah kemerdekaan. Rakyat mempunyai keinginan yang tinggi untuk mendalami ilmu mempertahankan diri. Beliau menggunakan kedudukannya sebagai kadi dengan mengiklankan diri memiliki ilmu persilatan yang tinggi dengan cogan kata Silat - Satu Kali Tumbuk Mati. Ilmu persilatan pada ketika itu amat berguna sebagai salah satu cara masyarakat Melayu menentang penjajah. Ramai ketua jabatan yang mendaftar untuk mempelajarinya. Pembelajaran dijalankan pada malam Jumaat bermula jam 12.00 malam. Dimulai dengan syarahan yang cukup menarik. Kemudian diikuti dengan belajar silat hingga jam 3.00 pagi. Setelah itu, mereka mandi dan menunaikan solat sunat tahajjud, solat sunat tasbih yang diimamkan oleh beliau serta diterangkan fadilatnya sehinggalah tiba waktu subuh. Setelah selesai menunaikan solat subuh, barulah mereka dibenarkan pulang.

Semakin lama semakin ramai orang yang datang belajar daripada beliau dan mula meninggalkan amalan yang bertentangan dengan Islam. Akhirnya aktiviti ini berterusan di balai Masjid Sultan Abu Bakar, walaupun beliau telah bersara daripada perkhidmatan awam. 
Kekuatan dan keistimewaan beliau melalui pelbagai cara mengembalikan masyarakat kepada ajaran Islam menjadi contoh yang boleh diteladani.

Sesungguhnya kesatuan ilmu silat, ilmu tasawuf dan pembinaan sahsiah yang berlandaskan al-Quran dan al-Sunnah telah membina jati diri beliau dengan mantap dan tekal. Kebolehan Kiai Haji Ahmad Shah ini dikagumi oleh segenap lapisan masyarakat sehingga ada dalam kalangan pengikut-pengikutnya dan orang ramai menganggap beliau sebagai wali.

\subsection{SUMBANGANNYA}

Sebagai seorang pemimpin agama dan tokoh tarekat, Kiai Haji Ahmad Shah telah memberi sumbangan besar dalam pemantapan agama Islam di Johor. Beliau sering menjadi rujukan permasalahan agama pada zamannya, Kiai Haji Ahmad Shah telah memperkenalkan dan memimpin ajaran Tareqat Qadiriyah Naqsyabandiyah ke daerah-daerah yang beliau pernah menyandang jawatan sebagai Kadi. Baginya syariat Islam adalah memperbaiki sesuatu yang lahir, manakala tareqat memperbaiki sesuatu yang tersembunyi (batin). Hakikat pula untuk memperbaiki segala rahsia yang ghaib dan makrifat merupakan matlamat terakhir iaitu hakikat Allah, zat, sifat dan perbuatannya. Beliau telah dapat melahirkan ramai anak didiknya yang menjadi ulama yang mencontohinya. Beliau mempunyai pengikut yang ramai, lebih kurang seramai 14,000 orang.

Selain pendidikan kepada anak-anak sebagai teras, Kiai Haji Ahmad Shah memegang prinsip bahawa setiap orang Islam wajib mempelajari ilmu fardu ain bagi pengesahan akidah dan ibadah di samping ibadah sembahyang sunat. Sebagai panduan kepada anak muridnya pada ketika itu beliau telah menulis panduan ilmu fardu ain tersebut di dalam kitabnya yang bertajuk Kitab Rohaniah pada tahun 1946. Kitab ini menghuraikan cara dan amalan Sembahyang Sunat Hajat, Sembahyang Sunat Tasbih di samping cara-cara untuk mengamalkan zikir untuk mendekatkatkan diri dengan Allah.

Negeri Johor adalah salah sebuah negeri di Tanah Melayu yang pernah diperintah oleh Jepun mulai Disember tahun 1941. Sebelum Jepun menduduki Tanah Melayu, tali barut Jepun yang dikenali sebagai F-Kikan mula berkeliaran di sekitar negeri Johor. Salah seorang telah menyamar menjadi peniaga sayur berjalan menuju ke arah Masjid Sultan Abu Bakar. Kiai Ahmad Shah tergerak hati untuk menegur atau menyapa penjual sayur ini. Penyamar Jepun ini tidak pandai berbahasa Melayu lalu beliau pun menyelak kain yang menutupi sayur tersebut. Tiba-tiba tentera Jepun tersebut tunduk menyembah beliau. Rupa-rupanya di dalam bakul sayur itu terdapat bom. Tentera Jepun ini diarahkan mengebom Masjid Sultan Abu Bakar. Polis peronda dipanggil dan menangkapnya. Keistimewaan inilah yang digunakan oleh beliau untuk memberi bantuan kepada masyarakat Johor yang berada dalam kesusahan.

Begitu juga apabila pihak tentera Jepun mengebom bangunan pentadbiran Kerajaan Negeri Johor di Bangunan Sultan Ibrahim yang terletak di Bukit Timbalan. Secara kebetulan Ahmad Shah sedang bertugas di situ. Atas kehendak Allah SWT, bom yang dilemparkan terkena penjuru menara bangunan tersebut. Namun begitu, bangunan itu hanya mengalami kerosakan sedikit di bahagian luar dan tidak menjejaskan langsung bahagian di sebelah dalamnya.

Pada tahun 1945, apabila Jepun menyerah kalah Tanah Melayu dikuasai oleh tentera komunis yang digelar Bintang Tiga. Pada masa itu, ramai orang Melayu yang diculik dan dibunuh. DYMM Sultan Ibrahim yang memerintah Johor telah meminta beberapa orang alim ulama untuk menjaga Istana Pasir Pelangi daripada sebarang kekacauan. Mereka termasuklah Ahmad Shah dan Kiai Haji Fadzil Banten. Ketika itu Kiai Fadzil adalah Mufti peribadi Sultan. Ahmad Shah sentiasa menurut titah Sultan Johor dan sejak dari itulah beliau bersahabat baik dengan DYMM Sultan Ibrahim dan dilantik sebagai penasihat Sultan.

Begitu juga semasa tragedi 13 Mei 1969, Kiai Haji Ahmad Shah adalah orang harapan masyarakat bagi diminta ilmunya untuk mempertahankan diri.

Di Rimba Terjun Pontian tempat kelahirannya, sebuah surau telah didirikan oleh Kiai Haji Ahmad Shah yang disebut bandarshah. (Kini dikenali sebagai Masjid Kiai Haji Abdul Jabar). Beliau membangunkan surau tersebut daripada wang persaraannya sebagai Kadi Besar Johor pada tahun 1957. Surau ini dibina dengan kos keseluruhan berjumlah RM 17,875.00. Dari jumlah tersebut RM 10,000 adalah wang ganjaran persaraannya manakala bakinya adalah curahan derma dari pengikut dan anak muridnya. Bagi beliau, kekuatan seorang ulama ialah melalui ilmu dan amalan yang terjalin erat. Menurutnya, ulama adalah pewaris nabi yang berjaya menggerakkan dan mempengaruhi orang lain melalui ilmu yang dimilikinya dan diterjemahkan melalui amalan yang dilakukan secara istiqamah. Untuk memiliki ilmu yang pelbagai itu, beliau telah melalui proses belajar ilmu dari pelbagai sumber. Ilmu yang diperolehi itu pula disebarkan kepada anak didiknya melalui pendidikan secara formal di sebuah pusat pengajian yang dinamakan bandarshah.

\subsection{PENGHARGAAN DAN PENGIKTIRAFAN}

Ketokohan dan kewibawaan seorang pemimpin itu biasanya dilihat melalui penghargaan dan pengiktirafan individu atau institusi kepadanya. Pada tahun 1935 apabila kembali dari menuntut ilmu, Kiai Haji Ahmad Shah dilantik menjadi imam di Masjid Jamek Pontian. Pada tahun 1936, apabila kadi daerah Pontian Haji Abdul Hamid meninggal dunia, Ahmad Shah telah dilantik menggantikannya sehingga tahun 1940. Pada tahun 1940, beliau dilantik menjadi Kadi Mersing. Oleh kerana tidak bersetuju dengan dasar pentadbiran Jepun beliau telah meletak jawatan sebagai Kadi dan membolehkan beliau mengkritik perlaksanaan dasar pentadbiran Agama Islam Johor tanpa sebarang sekatan. Kemudian, beliau meneruskan penyebaran Tareqat Qadiriyah-Naqsyabandiyah ke seluruh Johor. Dalam siri ceramahceramahnya, beliau memberikan semangat kesedaran agar bersatu-padu menentang pemerintahan Jepun yang penuh kezaliman.

Pada tahun 1947, beliau menjadi Kadi di Batu Pahat di samping mengembangkan Tareqat Qadiriyah-Naqsyabandiah dan beliau sebagai 'Syeikh". Pada tahun 1952, beliau dipindahkan menjadi Kadi Muar. Beliau terus mengajar tareqat ini di Muar dan mendapat sambutan yang menggalakkan kerana masyarakat Islam sangat dahagakan ilmu ketika itu.

Pada tahun 1955, beliau dilantik menjadi Kadi Johor Bahru seterusnya menjadi Kadi Besar Johor. Setelah bersara, Ahmad Shah terus menjadi pemimpin kepada Tareqat Qadiriyah-Naqsyabandiah. Beliau telah meninggal dunia pada 5 November 1971 . Ribuan murid dan pengikutnya datang menziarahi sehingga dilantik seorang anak muridnya mengaturkan upacara sembahyang jenazah secara bergilir-gilir dari jam 8.00 pagi hingga jam 4.00 petang di masjidnya yang sebelum ini disebut 'Bandarshah'. Kini, masjid tersebut ditukar kepada nama 
ayahnya yang juga merupakan tokoh sufi di kampung kelahirannya dan masjid kampong kelahiran beliau iaitu Masjid Kampung Rimba Terjun ditukar namanya kepada iaitu Masjid Haji Ahmad Shah.

\subsection{KESIMPULAN}

Kiai Haji Ahmad Shah merupakan tokoh sufi yang telah memberikan sumbangan yang besar dan berimpak tinggi kepada masyarakat Johor. Tokoh serba boleh ini telah meninggalkan corak pemikiran yang terbuka berbanding ulama lain pada zamannya. Sekalipun beliau telah kembali ke rahmatullah lebih 40 tahun, tetapi ilmu yang ditinggalkan kepada masyarakat dan anak didiknya masih diamalkan sehingga kini. Selain menjadi kadi di beberapa daerah di Johor, beliau juga adalah pemimpin Tareqat Qadiriyah-Naqsyabandiah, guru silat dan pemimpin yang gigih memperhambakan diri, tampil dengan mengharungi cabaran demi merubah masyarakat ke arah kebaikan. Sesungguhnya kehadiran Ahmad Shah adalah kurniaan Allah SWT yang telah mewarnai sejarah perkembangan Islam di negeri Johor.

\section{Rujukan}

Abdul Latiff Jufri @ al-Jufri/Masnoridah Mohd Masry, (2010). 40 Tokoh Ulama Johor, KGGAMB Cawangan Johor.

Abdul Kadir bin N.C. Muhammad, (2011). Awang Muhammad Jamil: Sumbangan terhadap Kemajuan Masyarakat Brunei Darussalam. (Bangi:Fakulti Sains Sosial dan Kemanusiaan UKM)

Abdullah Zakaria Ghazali dan Zainal Abidin Borhan (eds.).(1994). Johor: Dahulu dan Sekarang, Kuala Lumpur: Persatuan Muzium Malaysia.

Ahmad Shah, (1946). Kitab Rohaniah, Johor Bahru: The Anis Printing Work.

Andek Masnah Andek Kelawa, (2001). Kepimpinan Wanita Dalam Islam: Kedudukannya dalam Syariah, Bangi: Penerbit UKM.

Ghazali Mayudin (1988). Johor Semasa Pendudukan Jepun, Bangi: Jabatan Sejarah UKM.

H.M.W Saghir Abdullah, (1990). Syeikh Daud bin Abdullah Fatani: Ulama' Ulung dan Pengarng Terulung Asia Tenggara, Shah Alam: Kizbi.

HAMKA, (1990). Tafsir Al-Azhar, Singapura: Pustaka Nasional.

Jamal Mohd Lokman Sulaiman, (1999). Biografi Tuan Guru Dato' Haji Nik Abdul Aziz Seorang Ulama’ Serta Ahli Politik Malaysia Di Abad Ke 20, Sulfa Human Resources \& Development Selangor.

Kassim Thukiman, (2011). Sejarah Johor Dalam Pelbagai Perspektif, Skudai: Penerbit UTM Press.

Khazin Mohd. Tamrin dan Sukiman Bohari, (1981). “Orang Jawa Pontian: Kedatangan dan Kegiatannya Dalam Aspek Ekonomi dan Politik Tempatan”, Jurnal Jebat $U K M$, Bangi Selangor.

Khazin Mohd. Tamrin, (1992). Javanese Labour and The Development of Malaya, Kertas Kadangkala bil. 6, Fakulti Sains Kemasyarakatan dan Kemanusiaan UKM. Mohd. Sohaimi Esa, (1999). Ekonomi Orang Arab di Johor (1862-1942), Kota Kinabalu: Penerbit UMS.

Nurulwahidah Fauzi, (2012). Sumbangan Ulama Arab Hadrami dalam Pentadbiran dan Pendidikan Agama Johor: Syed Abdul Qadir Bin Muhsin Al-Attas, Syed Alwi bin Tahir Al-Haddad. Tesis PhD, Universiti Malaya.

Saghidon Dirhan, (2007). Biografi 40 Tokoh-Tokoh Terpilih Pontian Johor, Johor Bahru: Yayasan Warisan Johor.

Syed Naguib al-Attas, (1963). Some Aspects of Sufism: As Understood and Practised Among The Malays, Singapore: Malaysian Sociological Research.

Temuramah dengan Muhyiddin bin Ilham. Anak murid Kiai Haji Ahmad Shah pada 9 Oktober 2014.

Thajunnisa Mohamed Ibrahim, (2004), Tun Dr. Ismail, Kejora Timur yang Mengerdip, Kuala Lumpur: Utusan Publications \& Distributors.

Wahid Hasyim, (2014), Rencana Kepimpinan Efektif dalam Islam, http://racanaunwahas.blogspot.com 